\title{
A HISTÓRIA DO INCONSCIENTE OU A INCONSCIÊNCIA DE UMA HISTÓRIA? ${ }^{1}$
}

\author{
The History of Unconscious or the Unconscience of History?
}

La Historia del Inconsciente o ila Inconsciencia de una Historia?

Cesar Rey XAVIER

\begin{abstract}
Resumo: O conceito de inconsciente representa um fenômeno cuja história tem sido pouco ou nada discutida nos espaços acadêmicos adequados para este fim. Sua história ainda é pouco conhecida, particularmente nos currículos de formação em psicologia do Brasil, seja devido às políticas e ideologias intrínsecas aos programas de formação, seja simplesmente por puro desconhecimento. O presente trabalho se propõe a contar um pouco desta história, tendo por base, em especial, o trabalho de pesquisa do psiquiatra canadense de origem suíça Henri F. Ellenberger. Para esta empreita, será necessário o delineamento de alguns contornos e contextos que circunscrevem a relação deste conceito com o Romantismo alemão, sinalizando para o impacto que as diferentes conceituações de homem e de natureza daí oriundas deixaram como legado para os tempos atuais. Sem ter a pretensão, obviamente, de espelhar toda a abrangência do tema neste artigo, busca-se, ao menos, apresentar um quadro dos inúmeros meandros que este conceito carrega dos séculos passados, desfechando uma breve cronologia de nomes, épocas e pensamentos. Palavras-chave: Inconsciente; História da Psicologia; Romantismo.
\end{abstract}

\begin{abstract}
The concept of unconscious represents a phenomenon whose history hasn't been discussed at all within academic spaces meant for this. Its history is still not well known and, specifically at Brazilian undergraduate curriculums, all points that the most important part of the research traditions that created it is not transmitted, be it for the intrinsic politics and ideologies of the undergraduate programs, be it for mere ignorance. The present work proposes to tell a part of this story, being based, specially, upon the works of the Swiss-Canadian psychiatrist Henri F. Ellenberger. For such enterprise, it will be necessary to line out some contours and contexts that circumscribe the relation of this concept with the German Romanticism, pointing out the impact that different concepts of Man and Nature that came from there left as legacy for the current times. Obviously, without having the ambition of mirroring all of this topic's coverage in this article, at least it seeks to present a frame of the innumerous windings that this concept carries from past centuries, enclosing a brief chronology of names, times and thought.
\end{abstract}

Keywords: Unconscious; History of Psychology; Romanticism.

Resumen: El concepto de inconsciente representa un fenómeno cuya historia ha sido poco o nada discutida en los espacios académicos adecuados para este propósito. Todavía su historia es poco conocida, particularmente en los curriculum de graduación de psicología en Brasil, esto puede deberse a las políticas e ideologías propias de los programas de graduación o simplemente por pura ignorancia. El presente trabajo tiene como propósito contar un poco sobre esta historia, teniendo especialmente como fundamento el trabajo de investigación del psiquiatra suizo canadiense Henri F. Ellenberger. Con este propósito, será necesario delinear algunos contornos y contextos que circunscriben la relación de este concepto con el Romanticismo alemán, señalando el impacto que las diferentes concepciones de hombre y de naturaleza de ahí originadas dejaron como legado para nuestros tiempos. Por supuesto, no se pretende reflejar todo el alcance del tema en este artículo, tratamos por lo menos, de ofrecer una imagen de los numerosos meandros que a través de los siglos se le atribuye a este concepto, desenlazando en una breve cronología de nombres, épocas y pensamientos.

Palabras-clave: Inconsciente; Historia de la Psicología; Romanticismo.

\section{Montando um Cenário para uma História do In- consciente}

O conceito de inconsciente certamente figura entre os mais controversos da história do conhecimento. Sua simples menção já suscita certo incômodo, contrariando uma ciência que se respalda em princípios como os de "razão", "controle" e "materialidade". Ao lado de seu caráter polêmico, também desperta fascínio naqueles que

1 Conferência proferida no I Simpósio de Psicologia do Inconsciente, realizado em Curitiba (PR), 01 e 02 de novembro de 2008. não se contentam em submeter todas as faculdades humanas a estes princípios, abrindo-se brechas muito interessantes para a exploração de conteúdos que passariam abaixo da superfície dos domínios da ortodoxia científica. Ficaríamos por aí, não fosse o fato de que sua verdadeira história também é uma das mais ignoradas no métier acadêmico das chamadas "humanidades".

Por conta disso, não é raro que os estudantes se deparem com toda sorte de distorções acerca das origens do conceito de inconsciente, na medida em que sejam formados em ambientes com pouco fomento de leituras 
complementares acerca de sua verdadeira história, em especial nos cursos de graduação em psicologia do Brasil. Quando o leitor da psicologia se depara com o termo "inconsciente", é comum associá-lo quase que imediatamente ao nome de certos personagens bem conhecidos e alardeados pela mídia científica. Se fôssemos dar continuidade, aqui, ao usualmente conhecido a respeito deste conceito, dificilmente agregaríamos algo de novo à infinidade de artigos, resenhas, livros e trabalhos a respeito do inconsciente.

No entanto, o presente artigo convida o leitor a fazer um passeio não usual pela história do inconsciente, vislumbrando nuanças ainda pouco conhecidas, não só de sua história, como também do alcance conceitual que este fenômeno atingiu em tempos bem anteriores à moderna psicologia, onde figuram nomes que sequer aparecem nos currículos dos diversos cursos de graduação em todo país.

Ao contrário, portanto, do que possa o título deste artigo suscitar ao leitor, especialmente aos estudantes em formação, pouco tocaremos em nomes como os de Freud, Jung e seguidores, a despeito do fato de que seus nomes figurem entre os mais importantes teóricos do inconsciente, na mais recente história da psicologia e da psiquiatria dinâmica. A importância destes pensadores dispensa apresentações e a notabilidade de seus nomes não requer enfáticas menções. As teorias de Freud, Lacan, e, mais recentemente a de Jung, por exemplo, já partilham um status invejável nos cursos de formação em psicologia, desde o tempo em que esta ciência foi regulamentada no Brasil, há mais de quarenta anos. Não estaríamos tratando nada de essencialmente novo nesta temática se procedêssemos à mera reprodução do que estes autores disseram, porquanto suas teorias e trajetórias já são extensivamente difundidas e ensinadas nos espaços acadêmicos. Mas o que há de novo a dizer sobre este conceito? Em uma palavra: sua história.

Como é comum em qualquer meio "humano", e o acadêmico não é exceção, vez ou outra se presenciam algumas cristalizações de modismos e ideologias, traduzidos em clichês que preenchem as rodas de artistas e intelectuais. Foi assim com a noção de inconsciente. Quantas vezes este vocábulo deve ter figurado como o tema central de alguma roda de amigos, nos idos dos nos 70 e 80 do século que findou? $\mathrm{O}$ apelo à idéia de inconsciente ganhou tanta popularidade, que chegou a fazer frente mesmo à forte ortodoxia científica representada pelo behaviorismo, nos corredores acadêmicos brasileiros. Assim, por muito tempo, os currículos de formação nas faculdades se dispunham de forma polarizada: num pólo, os adeptos da corrente experimentalista, calcada no behaviorismo estadunidense, sob uma atmosfera epistemológica francamente avessa à noção do inconsciente, tanto quanto a tudo o que dissesse respeito à noção de subjetividade; no outro, os adeptos da corrente mais propriamente "clínica”, calcada na tradição que se consolidou com as observações e interações estabelecidas entre o médico e seu paciente. Não era o caso de inexistirem, além destas duas, outras opções teóricas para a psicologia, o que vem sendo confirmado pela penetração gradual, nos currículos de formação, de outras tantas teorias extremamente interessantes para esta ciência. Era o caso de que, simplesmente, num certo período, e ressalta-se que estamos tratando de Brasil, o apelo do behaviorismo era bastante atraente, na medida em que se pretendia, com esta escola teórica, a mais fidedigna e verossímil continuidade dos modelos já consagrados nas ciências naturais.

Um contraponto à altura, neste caso, só poderia advir de uma teoria ou conceito que fosse igualmente atraente, ainda que não se encaixasse propriamente nos moldes da ortodoxia científica. O conceito de inconsciente foi este atrativo, e as teorias que o representavam foram o contraponto. Particularmente, a psicanálise de Freud beneficiou-se desta popularidade, consagrando-se como uma teoria que podia fazer frente ao modelo epistêmico behaviorista. Não eram poucos os intelectuais que buscavam vincular suas investidas com os parâmetros estabelecidos por Freud, a respeito do inconsciente. Na arte, no direito, na filosofia, na antropologia, em todos os meios podia-se deparar com algum trabalho de reflexão neste sentido, nos quais, ao invés de se fundar os comportamentos humanos em esquemas de reforçamento, o pensador brasileiro podia compartilhar com Freud aquele gostinho de um saber proibido, reservado aos poucos escolhidos que se iniciassem nos recônditos mistérios do inconsciente humano.

\section{Traçando Metas "Conscientes" para um Artigo sobre o Inconsciente}

É hora de alertar o leitor, neste momento, para um possível equívoco: o objetivo do presente artigo não é discursar sobre a história do conceito de inconsciente no Brasil. Foi preciso fazer estas breves alusões para chegar ao foco de nossos interesses. Pode-se dizer que seja mais fiel à temática deste artigo colocar a questão da seguinte forma: o "objetivo geral" deste trabalho reside em discursar sobre a inconsciência da história do inconsciente no Brasil. Emprega-se aqui um trocadilho para tornar lúdica a seguinte crítica subjacente: na ânsia de importar modelos e conhecimentos prontos de países estrangeiros, os cursos de formação em psicologia no Brasil, por muito tempo, não se ocuparam em investigar mais a fundo aquilo que o bom pensamento acadêmico recomenda, isto é, as bases históricas e epistemológicas de qualquer modelo de conhecimento.

Em meio a distorções e incongruências de toda sorte, o conceito de inconsciente era ensinado apenas e tão somente sob a égide das autoridades que se consagraram com a psicologia, ignorando-se uma enorme leva de pensadores e de séculos que os antecederam, e que prepa- 
raram as bases para que o século XX pudesse assoberbar-se no exótico perfume de um conceito marginal. É chegado o momento de o leitor acadêmico brasileiro familiarizar-se com certas fontes históricas do conceito de inconsciente, em cujas águas beberam as personalidades que encabeçam boa parte dos currículos de formação em psicologia no país.

A fim de dar cabo do "objetivo geral" sublinhado acima, é interessante passar, sucintamente, pelos inúmeros aspectos em que este conceito já foi contemplado ao longo da história, num passeio pelas idéias de não poucos pensadores que, desde o século XVII (e isto já é um recorte cronológico) vêm refletindo, compilando e sistematizando indícios, relatos e experiências a respeito do fenômeno do inconsciente. A fim de discursarmos, então, sobre o que ficou "inconsciente" a respeito desta história, mergulharemos em águas nada ortodoxas com respeito ao que usualmente se ensina deste fenômeno. $\mathrm{O}$ inconsciente possui uma história que precisa ser conhecida dos acadêmicos brasileiros, livre de clichês e ideologias. Contemo-la, então, com o espírito do verdadeiro pesquisador.

Se quisermos contar uma história mais "consciente" a respeito do inconsciente, alguns caminhos são necessários e mesmo inevitáveis. Seria temerário, e mesmo inviável, não contar com o recurso precioso da leitura de Henri F. Ellenberger (1905-1993), particularmente de sua obra intitulada The Discovery of the Unconscious ("A Descoberta do Inconsciente"), lançada em 1970. O leitor que perceber isto já se encontra no início de uma boa jornada que podemos chamar aqui de "despertar". Por que empregar este termo aqui? Diríamos que é a melhor palavra para expressar o impacto que qualquer estudante sente quando trava contato com esta obra.

Como é comum na formação de qualquer leitor de psicologia brasileiro, recebe-se a "história" da psicologia de modo bastante tendencioso, com recortes sem muito sentido, despojados de momentos e autores essenciais para uma compreensão mais fidedigna desta história, alienados de tudo que circunscrevia o universo mental humano antes da psicologia tornar-se "ciência moderna". A leitura de Ellenberger descortina inúmeros fatos e personagens da história, não só da psiquiatria e da psicologia, mas da própria filosofia, revelando tons, cores e matizes que embaraçariam qualquer professor de história da psicologia que resolvesse contá-la sem o recurso desta obra. Cada vez que se resolve pegar em mãos a obra de Ellenberger, é possível ampliar os horizontes do entendimento histórico de um modo que, invariavelmente, transforma a compreensão que se tem do próprio ofício de psicólogo.

As passagens lá documentadas, relatadas ao estilo suave que bem caracteriza Ellenberger, aliadas à sua interpretação justa e sensata dos diversos acontecimentos, pintam um quadro no mínimo surpreendente para qualquer estudante de psicologia que tenha sido "formatado" pelas tradicionais formas de se contar a história desta ciência. A história "rasa", que infelizmente ainda predomina em muitas didáticas, é pobre em articular os feitos dos autores com seus respectivos "espíritos de época" (ou Zeitgeist), alienada de toda uma contextualização pré-científica e pré-psicológica que nos revela a verdadeira essência do fenômeno do inconsciente. Quem lida com este conceito hoje, nas diversas clínicas, hospitais e consultórios do país, não imagina que a base do iceberg de sua história é muito mais rica e profunda do que sua ponta aparente.

Seria uma esperança improdutiva querer transmitir aqui toda a abrangência e profundidade despertadas com A Descoberta do Inconsciente. Mas este artigo tem a esperança de, ao menos, inspirar o leitor a seguir os passos desta investigação histórica, bem como ajudar a retirar o véu que encobre a legítima história não só do inconsciente, mas de uma série de eventos psicológicos a ele relacionados.

Dando sequência a esta linha de raciocínio, em que situamos esta análise histórica em uma sucessão de "dependências", também é prudente colocar o mesmo grau de inviabilidade em se contar uma história do inconsciente sem adentrar a história do que Ellenberger salienta como "psiquiatria dinâmica". Com efeito, se a psicologia de corrente mais "experimental" nasceu de um casamento das tradições filosófica e fisiológica, no seio dos laboratórios de grandes nomes como Wundt, Titchener, Helmholtz e Ebbinghaus, pode-se dizer que aquela sua outra corrente, que alguns autores gostam de chamar de "clínica", haurida no seio das observações de homens como Freud, Jung, Bleuler e tantos outros, não se restringe às duas tradições referidas, a da filosofia e a da fisiologia. Pois a corrente da psicologia que se consolidou no seio de clínicas e hospitais psiquiátricos, que hoje figura entre as práticas de muitos psicólogos de diferentes abordagens, forjou-se principalmente com a influência da medicina, particularmente numa linhagem de psiquiatras que a história chama de Psychiker (Ellenberger, 1970).

É principalmente a esta corrente que nos referimos quando empregamos a expressão "psiquiatria dinâmica", expressão esta que dá forma ao subtítulo da obra supracitada, a saber, "The History and Evolution of Dynamic Psychiatry". Ora, o termo "dinâmico", contrapõe-se, na linguagem científica, a "mecânico", que passa a idéia de estruturas rígidas e estáticas. Assim, podemos entender a contraposição entre uma tradição de pensadores da mente humana chamados de "psíquicos" (Psychiker) e outra chamada de "somáticos" (Somatiker). Nesta, encontramos a psiquiatria mais tradicional, que vingou com mais vigor em meio às pesquisas em fisiologia do século XIX, dando destaque ao corpo (soma); naquela, encontramos a psiquiatria mais "marginal", que se consolidou em meio a práticas heterodoxas de pesquisa, dando destaque à mente (psique). Afinal, nem só de estruturas rígidas e paradas vivem os fenômenos mentais. Felizmente, ao longo da história, muitos se deram conta disso, particularmente da impossibilidade de se "reduzir" a fenomenologia intrín- 
seca dos processos mentais às suas estruturas paralelas e subjacentes da fisiologia e neurologia humanas.

Ainda é preciso falar de mais uma "dependência" nos anais da história do inconsciente, antes de adentrarmos os diversos momentos da história propriamente ditos, seguindo os passos da senda construída por Ellenberger. Em curtas palavras, é impossível contar uma história do inconsciente sem a gestação de um profundo entendimento do Zeitgeist que inundou a Alemanha de um novo estilo de se pensar o homem e a natureza, na virada do século XVIII para o XIX, o Romantismo.

\section{O Cosmos Romântico: Homem - Inconsciente - Natureza}

Uma das chaves mais preciosas legadas pelo Romantismo está em revelar ao pensamento ocidental outra forma de relacionamento com a natureza, que não aquela que se consagraria com o pensamento moderno. Com efeito, o Romantismo é um movimento "anômalo" para este pensamento, espremido entre um mecanicismo tardio, uma racionalidade iluminista que se encontrava em seu término, e um positivismo que, a posteriori, soterraria suas lembranças, deixando a falsa associação do Romantismo apenas com artes plásticas, literatura ou música. Contrariando em muito esta equivocada associação, o Romantismo, na verdade, foi também, e principalmente, um movimento filosófico e científico, que se propunha a uma conceituação diferenciada da natureza.

Trata-se de um movimento que nadou contra a correnteza da então tendência racionalizante que "impermeabilizava" a Europa, por assim dizer, de boa parte de seus motivos folclóricos, místicos e arcaicos. A chamada "Era das Luzes", mais conhecida por Iluminismo, espalhava seu movimento de secularização pelo continente de um modo que, tal como o filtro d'água que segura as impurezas, mas também retém os preciosos minerais, acabou por colocar, no mesmo "pacote", o que precisava ser expurgado da sociedade com tudo aquilo que poderia ter sido conservado de suas ancestralidades culturais. É certo que a Europa do século XVIII beneficiou-se sobremaneira com as diversas reformas sociais implementadas pelo Iluminismo. Se depositarmos confiança no fenômeno do Zeitgeist, poderíamos imaginar que cada período experimenta o clima intelectual e emocional de que precisa. Assim, o Mecanicismo, tão criticado pelos intelectuais de hoje, de fato foi necessário e benéfico para o contexto do século XVII. No caso das "Luzes”, a pauta do momento era combater as paixões que desnorteavam a consciência humana, submetendo-as à soberania da razão, como reiterava um de seus maiores expoentes, Immanuel Kant (1724-1804).

Mas o tempo, como a psique, também é "dinâmico". Novas necessidades surgem, novas buscas de sentido para o rumo que a história toma são sentidas por gera- ções, e aquilo que outrora havia sido o símbolo de toda uma era, passa a representar um fardo, como um peso desnecessário na bagagem da viagem histórica. Como qualquer Zeitgeist, o Iluminismo deixou suas sequelas. Seria difícil convencer os habitantes daquela época de algo que para nós, hoje, afigura-se óbvio: a razão não está sozinha no trono da existência e da consciência humana. Não obstante, já se podiam antever os primeiros sinais de desilusão, quando da primeira sentença que abre o último dos discursos de um homem "iluminado": "Eisme, portanto, sozinho na terra" é a frase que iniciaria a compilação das dez reflexões que Jean-Jacques Rousseau (1712-1778) redigiu após uma série de lapidações acerca de sua moral e idéias, que sofreu em fins dos anos 60 do século XVIII.

Publicado postumamente por um amigo sob o título Les rêveries du promeneur solitaire ("Os devaneios do caminhante solitário”), a obra nos faz perceber, na figura de Rousseau, um dos ícones que simbolizam a transição do Iluminismo para o Romantismo. Se em Fichte podemos enxergar o precursor filosófico do enaltecimento do "Eu", que tanto inspiraria o grupo liderado pelos irmãos Schlegel, em Rousseau jorram as primeiras águas poéticas que desembocariam no entusiasmo do chamado PréRomantismo alemão, conhecido pela expressão Sturm und Drang ("Tempestade e Ímpeto"). Nos Devaneios, Rousseau prova o "gosto” de sua própria existência, num clima bucólico que registra o único refúgio que encontra: a própria interioridade. Mas quanto mais fundo nela mergulha, mais presente se torna o aroma das flores e minúcias do campo, que atuavam como o cenário de suas introspecções, enquanto percorria por margens de lagos, bosques, pastagens e videiras.

Para Rousseau, o homem só encontra sua plenitude no resgate desta relação de simplicidade com a natureza. $\mathrm{Na}$ quinta daquelas caminhadas, há um momento que vale citar para o contexto deste tópico. Diante da própria solidão, Rousseau se pergunta:

De que desfrutamos numa tal situação? De nada de exterior a nós, de nada a não ser de nós mesmos e de nossa própria existência; enquanto este estado dura bastamo-nos a nós mesmos como Deus. O sentimento da existência, despojado de qualquer outro apego é por si mesmo um sentimento precioso de contentamento e de paz, que sozinho bastaria para tornar esta existência cara e doce a quem soubesse afastar de si todas as impressões sensuais e terrenas que vêm continuamente nos afastar dela e perturbar, na terra, sua suavidade. Mas a maioria dos homens, agitados por paixões contínuas, conhece pouco esse estado e tendo-o experimentado apenas de forma imperfeita, durante poucos instantes, dele não conservam senão uma idéia obscura e confusa que não lhes faz sentir seu encanto (Rousseau, 1995, p. 76). 
Mas o terreno preparado pelo suíço de língua francesa só veria a germinação dos ideais românticos em solo alemão. A Alemanha, por uma série de motivos sociais, religiosos e políticos, dos quais não há espaço hábil para tratar aqui, seria a nação onde novas idéias, avessas ao predomínio da razão, iriam se constelar como início de um novo espírito de época, constelando grupos e movimentos que ressaltariam o papel da subjetividade como parâmetro da própria existência. É, portanto, na contracorrente da tendência iluminista que iria se firmar o Romantismo, um movimento cujo ápice perdurou por cerca de três décadas, ultrapassando as fronteiras da Alemanha, contagiando diversos outros países e continentes. O professor de filosofia e história das idéias J. J. Clarke (1993), na obra que escreveu nos anos 90, sob o título In Search of Jung, dedica um capítulo à relevância do Romantismo para a psicologia do inconsciente que se consolidou no século XX. Escreve:

Não padece dúvida [comentando sobre os românticos] que conseguiram redefinir a questão da natureza humana e iniciaram uma exploração, de vastas conseqüências, das estruturas interiores da psique (...) A maneira como viam a natureza, um todo orgânico vivo no qual a consciência era parte integral - na verdade, crucial -, plantou-os firmes na tradição mais antiga que florescera nos mundos medieval e da Renascença, mas que fora marginalizada no período do Iluminismo (Clarke, 1993, p. 89).

Um dos grandes motes de toda a filosofia e ciência ocidentais sempre girou em torno da relação homemnatureza, muitas vezes traduzido por observador-objeto observado. Assim jaz o homem: uma criatura que tem consciência de si, cercada por uma natureza que o envolve tal qual o útero materno ao embrião, por todos os lados, permeado de mistérios. O que é a natureza para nós? E o que somos nós com relação à natureza? Qual deveria ser o melhor modo de se relacionar com esta entidade chamada "natureza"? Explorando-a, controlando-a, adaptando-se a ela...?

É sabidamente possível, inclusive, explicar cada um dos períodos da história mediante tal categoria. $\mathrm{O}$ Romantismo oferece sua resposta, em grande parte resgatando saberes pré-modernos, alguns até considerados arcaicos, fartos nos períodos medieval e renascentista. Possivelmente, a obra em língua portuguesa que melhor exprima o que foi o movimento romântico tenha sido a que J. Guinsburg organizou em fins dos anos 70, com a reunião de treze ensaios e uma cronologia do movimento romântico. Comentando a crítica romântica aos abusos cometidos em nome da razão, Gerd Bornheim, um dos ensaístas desta obra, afirma que "a intelectualização, quando ditatorial, leva inevitavelmente a um afastamento da natureza, ficando esta reduzida a objeto do pensamento racional, quer científico, quer filosófico" (Bornheim, 2005, p. 79).

Eis uma das sequelas da razão, percebidas com acuidade pelos românticos: a soberania da razão afastou o homem da natureza, afastou o homem de si mesmo, uma vez que ele também é natureza! A razão, isolada em seu pedestal, "impermeabiliza" a relação do homem com a natureza. Ela é como um trono ideal, onde o homem se entende “lógico", mas no qual, se ali permanecer, perderá todo o sentido da totalidade que o abarca. O Romantismo aspirava por esta totalidade, em resgatar sua sintonia com ela, a que chamamos de "natureza". E o antídoto encontrado por poetas e pensadores como Göethe, Novalis, Hölderlin, Schleiermacher e os irmãos Schlegel, dentre outros, estaria em compensar a frieza típica de uma razão fleumática pelo calor passional que exalava por meio do lema Sturm und Drang. Era, então, o "assalto", e não mais a razão, a tônica da autocompreensão humana.

Se o inconsciente pode parecer um fenômeno distante, ele não é nada frio para os românticos. No calor de suas abordagens passionais, note-se que até mesmo o conceito de "genialidade" que, de imediato, poderia associar-se ao ideal iluminista da razão, altera-se radicalmente sob a égide do Romantismo, ganhando um sentido totalmente reformulado. A esse respeito, Bornheim comenta que:

Não é a razão que define o gênio, e sim o berço último de nossas idéias, aquela região subterrânea que nos habita e que logo mais será batizada pelos românticos de inconsciente. Essa zona obscura é que deve ser explorada, pois ela é a zona original, raiz coincidente com o divino, verdade última e ponto de partida do homem (Bornheim, 2005, p. 82).

Eis o vínculo romântico do homem com a natureza: seu inconsciente. Este é, aliás, um dos sentidos que se perderam com os rótulos pós-modernos que se agregaram à noção de inconsciente. Muito provavelmente, nossos dias busquem compensar esta perda com as atuais campanhas em prol da ecologia, nas quais vemos ressurgir a velha noção romântica do elo indissolúvel entre o homem e a Terra, não mais como apartado dela. Benedito Nunes, outro dos ensaístas da obra supracitada, diria que:

Desse ponto de vista, a Natureza, que não foi para o Romantismo apenas a mais abrangente de suas tematizações, mas o foco precípuo sob o qual a imaginação intuitiva se afirmou e se exerceu, voltou a ser contemplada pelos românticos através da perspectiva de coesão mágica, de envolvimento analógico entre palavras e coisas, da compreensão pré-clássica do mundo, dominante do Medievo à fase renascentista (Nunes, 2005, p. 67).

Dentre todos os pensadores românticos que espelham a relação homem-inconsciente-natureza, certamente o que 
melhor conseguiu traduzir este elo em uma linguagem filosófica foi Friedrich Wilhelm Joseph von Schelling (1775-1854), o líder do grupo que se destacaria do seio do Romantismo sob o título de Naturphilosophie (filosofia da natureza). De tudo quanto possa ser dito sobre este pensador, nada sintetiza melhor seu pensamento do que a sentença dita por ele mesmo, na Introdução de Ideen zu einer Philosophie der Natur ("Idéias para uma Filosofia da Natureza"), publicada em 1797: "a natureza deve ser o espírito visível, o espírito a natureza invisível" (Schelling, 2001, p. 115). Desse modo - afirmam Reale \& Antiseri (1991):

Schelling chega à conclusão de que a natureza é produzida por inteligência inconsciente, que opera no seu interior, que se desenvolve teleologicamente em graus, ou seja, em níveis sucessivos, que mostram finalidade intrínseca e estrutural (p. 74).

Daí porque, para os românticos, o termo "inconsciente", como afirma Ellenberger, "era o próprio fundamento do ser humano enquanto ser enraizado na vida invisível do universo e, portanto, a verdadeira ligação unindo homem com natureza" (1970, p. 204). Distanciando-se criticamente do mecanicismo que havia guiado a compreensão da natureza desde o século XVII, Schelling visualiza nesta não mais uma hierarquia de causalidades mecânicas, ou mesmo divina (como em São Tomás de Aquino), mas uma analogia que em muito resgata a antiga noção agostiniana da natureza como espelho do sagrado, na qual traça uma diferenciação semântica da idéia de natureza para dois sentidos assim denominados: natura naturans e natura naturata. Escrevia ele nas Idéias:

A natureza, na medida em que aparece como natureza, quer dizer, como esta unidade particular, já está, por conseguinte, enquanto tal, já fora do absoluto, não a natureza como o próprio ato absoluto de conhecimento (natura naturans), mas sim a natureza como mero corpo ou símbolo daquele (natura naturata). No absoluto, ela é, como uma unidade, com a unidade oposta - que é a do mundo ideal -, mas, justamente por isto, no absoluto, nem a natureza é como natureza, nem o mundo ideal como mundo ideal, mas sim ambos como um só mundo (Schelling, 2001 p. 135, sem grifos no original).

Comentando sobre esta analogia, a pesquisadora brasileira Márcia Gonçalves escreve:

A possibilidade de se entender uma possível conciliação entre natura naturans e natura naturata encontra-se na idéia de que a natureza é uma espécie de "espelho", no qual se refletiria a própria imagem do Criador (imago Dei), ou ainda pela metáfora de um livro sagrado, já presente em santo Agostinho. Essa metáfora, também denominada "analogia hermenêutica", compara a natureza com a sagrada escritura (Gonçalves, 2006, p. 24).

Esta metáfora estabelecida entre natureza e espírito, mediada pelo inconsciente, representa certamente a grande revolução na cosmovisão do homem moderno, mas que, como dissemos atrás, foi condenada a permanecer na obliteração ocasionada pelo Positivismo, o movimento que vigorou a partir da segunda metade do século XIX, e que consagrou o ideal de ciência moderna, pautada em princípios bem diferentes dos nutridos pelo Romantismo. Com efeito, o desenvolvimento do conceito de inconsciente, como dissemos ao início deste tópico, representa uma "anomalia" com respeito à modernidade, e muito de sua consolidação se deve a pesquisas "marginais", posto que o século XIX, porquanto possa ser considerado um momento ápice da modernidade, teria de se definir entre uma visão de mundo romântica e outra positivista. Sabemos qual foi a escolha, e este é um dos motivos, talvez, pelos quais a história que Ellenberger nos apresenta é ainda tão pouco conhecida e difundida.

Mas outro equívoco, que se somaria àquele que se comete nos currículos e nas didáticas de formação, por ignorar as origens, digamos, "pré-psicológicas" do conceito de inconsciente, incorreria se parássemos igualmente no Romantismo, a fim de rastrear seu nascedouro. Uma investigação do que ocorreu nos bastidores do século XIX não nos basta. É preciso avançar mais na cronologia que dá início à modernidade. Quando investigamos atentamente os primórdios de algum Zeitgeist, ele nos revela características das cosmovisões que o antecederam. Avancemos um pouco mais, então, na "Descoberta do Inconsciente".

\section{Seguindo os Passos de Ellenberger}

Tendo como ponto de partida um esboço geral das diversas formas de tratamento primitivo, onde era comum a convivência entre medicina, religião e procedimentos mágicos, Ellenberger constrói uma trilha minuciosamente bem elaborada até chegar à figura de Franz Anton Mesmer (1734-1815), particularmente dando destaque à polêmica que logo se constelou, em fins do século XVIII, entre ele e Johann Joseph Gassner (1727-1779), um padre que era pródigo em praticar o exorcismo. Neste momento da obra, vemos de que modo o legado de Mesmer suplantou as práticas do exorcismo, oferecendo em seu lugar explicações baseadas no que denominou de "magnetismo animal". A obra de Mesmer também é situada por Ellenberger como um ponto de partida para o que ele chama de "a emergência da psiquiatria dinâmica", título de um dos capítulos de sua obra, que terminaria por desembocar na psiquia- 
tria do século XIX, bem como na psicologia que, ao final deste século, preparava-se para emancipar-se sob a égide de seus primeiros mentores.

A analogia que parece atuar como um "farol" nos escritos de Ellenberger reside em uma comparação entre algumas das modernas técnicas de psicoterapia e as dos curandeiros de outrora. Para ele, existem semelhanças inegáveis, principalmente se levarmos em conta os processos inconscientes de fundo, que participam do processo terapêutico toda vez que duas ou mais pessoas se "escutam" atentamente. Afirma ele:

Por muitos anos, os relatos de curas realizadas por curandeiros, xamãs e tratamentos considerados primitivos despertaram pouca atenção entre os psiquiatras. Tais relatos eram considerados como histórias estranhas, de interesse apenas a historiadores e antropólogos. (...) Hoje já dispomos de uma avaliação diferente e mais justa. (...) A pesquisa histórica e antropológica trouxe à tona importantes documentos, evidenciando o emprego, entre os primitivos, dos muitos métodos utilizados atualmente pela moderna psicoterapia, mesmo que em um formato diferente. (...) O estudo da terapêutica primitiva, portanto, é de interesse não apenas dos historiadores e antropólogos, mas também de grande importância enquanto base para uma nova ciência (Ellenberger, 1970, p. 3).

Em outras palavras, o que Ellenberger quer nos dizer é que a diferença das nomenclaturas não altera tanto a semântica das terapias às quais aludem. De toda a fenomenologia em jogo aí, o autor esmera-se em isolar aquela que interessa aos propósitos da história contada, ou seja, isola o fio de Ariadne que aproxima práticas modernas de certas práticas antigas.

Na prática de Mesmer, em que se empregava, além da própria presença do magnetizador, o recurso de metais que agiriam como condutores do "fluido" (algo que hoje poderíamos, para efeito de nossa linguagem, chamar de "energia"), o objetivo estava em restaurar o fluido animal desequilibrado da pessoa enferma. Ellenberger nos oferece um quadro bem resumido desta doutrina:

O sistema de Mesmer, tal como ele expôs em 27 pontos no ano de 1779 , pode ser resumido em quatro princípios básicos. 1 - um fluido físico sutil preenche o universo e forma um meio de conexão entre o homem, a terra e os corpos celestiais, e também entre homem e homem. 2 - a doença origina-se de uma distribuição desigual deste fluido no corpo humano; a recuperação é alcançada quando o equilíbrio é restaurado. 3 - com a ajuda de certas técnicas, este fluido pode ser canalizado, armazenado e transferido para outras pessoas. 4 - desta maneira, a "crise" pode ser provocada nos pacientes e as doenças curadas (Ellenberger, 1970, p. 62).
Assim, uma vez instalada a senda da psiquiatria dinâmica na Europa setecentista, três grandes etapas podem ser delineadas, começando pelo exorcismo, evoluindo para o magnetismo, e migrando para as modernas práticas de hipnose. Nesta transição, alguns personagens despontam como "pedras angulares" na mudança de conceitos. Comecemos pelo nome do Marquês de Puységur (17511825), um dos principais responsáveis pela transição do magnetismo animal de Mesmer para a rota que conduziria ao hipnotismo. Nas palavras de Ellenberger:

Sempre chega o tempo em que a criação emancipa-se de seu criador e toma seu curso independente de vida. Mesmer mal tinha começado a desvelar sua doutrina quando um dos seus mais fiéis discípulos, o Marquês de Puységur, fez uma descoberta que estava para dar um novo curso para a evolução do magnetismo. (...) Um de seus primeiros pacientes foi Victor Race, um jovem camponês de vinte e três anos de idade, cuja família tinha estado a serviço da família Puységur por várias gerações. Victor, que estava sofrendo de uma doença respiratória branda, foi facilmente magnetizado e, naquele estado, apresentou uma crise muito peculiar. Não houve quaisquer convulsões nem movimentos desordenados, como era o caso com outros pacientes; a bem dizer, ele entrou em um estranho tipo de sono (Ellenberger, 1970, p. 70).

É importante que o leitor compreenda a estreita ligação do fenômeno do inconsciente com todas as formas de estado psíquico nas quais possam ser investigadas algumas "janelas". Qualquer tipo de transe ou estado alterado de consciência remete o investigador à noção de inconsciente, e os pesquisadores de outrora não tinham pudores para encarar de frente estes fenômenos. Ellenberger confere especial destaque, inclusive, às pesquisas realizadas com fenômenos mediúnicos, muitas das quais deram a base para publicação de obras que não passaram despercebidas à época. No caso das sessóes magnéticas, era comum que as pessoas manifestassem convulsões. Mas o próprio estado mental de sonolência já configura uma brecha para o inconsciente. E foi esta a janela pela qual Puységur enveredou, percebendo que o tipo de transe no qual ingressavam seus pacientes era bem mais sereno do que o usual nas sessões de magnetismo. Como afirma Ellenberger (1970, p. 71), a analogia daquele sono magnético com o sonambulismo natural foi logo reconhecida, daí o nome "sonambulismo artificial". Somente algumas décadas mais tarde, o médico inglês James Braid (1795-1860) emprestaria um caráter mais científico ao fenômeno, cunhando o termo "hipnose".

No exorcismo de Gassner, portanto, podemos identificar um "agente espiritual" como o fator desencadeante das enfermidades. Em Mesmer, a explicação girava em torno da idéia do "fluido". E em Puységur é na "vontade" do magnetizador que está o fator desencadeante do 
“sono magnético" (Ellenberger, 1970). Mas isto mudaria com a explicação oferecida por outra figura lendária, a do magnetizador de origem portuguesa conhecido por Abade Faria (1746-1819), a quem Ellenberger atribui a teoria "animista" para o tipo de transe que se verificava nos tratamentos. Ao invés de situar o fator principal em algum agente espiritual, fenômeno natural, ou na vontade do magnetizador, o padre situa-o no próprio sujeito que se submete ao tratamento, entendido aí como um potencial intrínseco que seria mais manifesto a certos tipos de indivíduos. A evolução gradual de todas estas descobertas conduziria, ao final do século XIX, às duas grandes escolas de hipnose que surgiram na França: a escola de Nancy, liderada por Auguste Ambroise Liébeault (1823-1904) e Hippolyte Bernheim (1840-1919) e a escola de Salpêtrière, liderada por Jean-Martin Charcot (18251893), cujas práticas e idéias estão detalhadamente retratadas na obra de Ellenberger.

Mas não é só no terreno das diversas formas de hipnose que encontramos os vestígios antecipados do conceito de inconsciente. Como dissemos anteriormente, as "janelas" para este fenômeno são muitas e surpreendentes. É o caso das investigações perpetradas por Justinus Kerner (1786-1862), o primeiro magnetizador a construir uma biografia de Mesmer, mas que ficou mais conhecido pelo trabalho desenvolvido com uma paciente que se encontrava perto da morte, Friedericke Hauffe, conhecida posteriormente como Die Seherin von Prevorst ("A Vidente de Prevorst”), título da obra que publicou em 1829 a respeito dos inúmeros fenômenos que circunscreviam a vida da médium (Ellenberger, 1970). Nas palavras do autor da Descoberta do Inconsciente, esta "foi a primeira monografia devotada a um paciente individual no campo da psiquiatria dinâmica" (Ellenberger, 1970, p. 81).

Na história do inconsciente, há também um braço das pesquisas que tangenciam o que hoje conhecemos por “parapsicologia”. É deste bojo que desponta a figura de Frederick Myers (1843-1901), um dos grandes sistematizadores do conceito de inconsciente. Myers também foi o mentor do conceito nomeado por "função mitopoética do inconsciente”, uma idéia pela qual o próprio Ellenberger manifesta pesar, pela falta de uma continuidade que um fenômeno tão interessante suscitava. Sob o entendimento desta função haveria segundo Myers, nas expressões do inconsciente, uma tendência para tecer fantasias, quase como uma linguagem "romanceada" (Ellenberger, 1970).

Não foram poucos os que se envolveram com o fenômeno do inconsciente. E não poderíamos deixar de mencionar, para fins de enquadramento da modernidade, o primeiro pensador que se tem registro nesta era a elaborar um conceito deste fenômeno com elementos puramente psicológicos, o filósofo alemão Gottfried Wilhelm von Leibniz (1646-1716). Com sua teoria da "monadologia", Leibniz criou um conceito que fica a meio caminho entre a matéria e o puro pensamento, as "mônadas", uma noção que busca sustentar metafisicamente a base da própria matéria, noção esta intrinsecamente ligada à função da percepção. Com as mônadas, Leibniz antecipa, de certo modo, muito do que cerca os paradoxos quânticos da física de partículas, mais precisamente a imaterialidade dos átomos, que se revelou ser mais a regra do que a exceção. Sob esta noção, tudo seria composto por mônadas, e só tomaríamos consciência das coisas a partir do momento em que uma quantidade suficiente delas se constelasse para nós. Assim, durante o ruído provocado pela queda de uma chuva, por exemplo, o som de cada uma das gotas nos é inconsciente, mas sua somatória se torna consciente, uma apercepção (Leibniz, 1720/1992). Um modelo mais dinâmico para este conceito seria apresentado um século mais tarde pelo filósofo e pedagogo alemão Johann Friedrich Herbart (1776-1841), combinando a idéia de percepção leibniziana com a noção de "associação".

Neste modelo, o "limiar de consciência" só é atualizado por idéias coerentes entre si, não sendo possível a simultaneidade de idéias contraditórias na consciência. Idéias opostas ou diferentes às que se firmaram na consciência são postas de lado, pairando abaixo do limiar de consciência. A consciência seria uma superfície cujo cenário está em troca constante. As percepções lutam por sua emergência na consciência e não há lugar para contradições. A contenda entre as idéias é decidida pela intensidade das associações estabelecidas entre elas, ou seja, o grupo das idéias que se fortalece pelas associações construídas é o que consegue vingar à luz da consciência (Schultz \& Schultz, 1996; Ellenberger, 1970).

Na obra de Ellenberger, dentre os diversos pensadores que receberam destaque especial no tocante ao conceito de inconsciente, temos na figura de Carl Gustav Carus (1789-1869), médico e pintor, talvez o primeiro grande sistematizador do conceito de inconsciente. De acordo com Ellenberger (1970), Carus era: “(..) notável também pelo seu trabalho sobre psicologia animal e sobre fisiognomia, e particularmente por seu livro Psyche, o qual foi a primeira tentativa de dar uma completa e objetiva teoria sobre a vida psicológica inconsciente" (p. 207).

As primeiras palavras de Carus na obra Psyche, de 1846, já falam por si próprias:

(...) a chave para o conhecimento da natureza, da vida consciente da alma, reside no domínio do inconsciente. Isto explica a dificuldade, se não a impossibilidade, de conseguir uma real compreensão do segredo da alma. Se encontrar o inconsciente a partir da consciência fosse uma impossibilidade absoluta, então o Homem deveria desistir de algum dia adquirir tal conhecimento, isto é, o conhecimento de si mesmo. Mas, se esta impossibilidade é apenas aparente, então a primeira tarefa de uma ciência da alma é a de estabelecer como o espírito do Homem é capaz de mergulhar nestas profundezas (Carus, citado por Ellenberger, 1970, p. 207, grifos nossos). 
Se é certo que o século XIX consagrou a ciência em seus moldes mais fisicalistas e positivistas, por outro lado a história ainda haverá de acertar as contas com a enorme quantidade de material produzido acerca do inconsciente durante aquelas décadas. Pouco se fala, no ensino das disciplinas de história da psicologia, do pensador e naturalista alemão Gotthilf Heinrich von Schubert (17801860), um dos grandes antecipadores dos escritos de homens como Teilhard de Chardin e Henri Bergson, bem como de muitas das idéias defendidas por Freud e Jung. De acordo com Von Schubert, no seio da natureza haveria resquícios de nossa ancestralidade, manifesta em mitos (um prenúncio do conceito de inconsciente coletivo de Jung). Criou a noção de "ânsia de vida" contrabalançada pela "ânsia de morte" - um prenúncio do conceito de pulsões no pensamento de Freud (Ellenberger, 1970). Foi o autor de "Die Symbolique des Traumes ("O simbolismo dos sonhos", de 1814), obra na qual traça uma diferenciação entre linguagem pictórica nos sonhos e linguagem verbal no estado de vigília (a mesma diferenciação que Freud estabelece posteriormente em sua obra $A$ interpretação dos sonhos).

Por falar em sonhos, é "recomendável" mencionar o nome de Karl Albert Scherner (1825-1889), o primeiro pensador de que se tem registro a interpretar os próprios sonhos, e publicá-los em um livro, Das Leben des Traumes ("A vida dos sonhos", de 1861). Scherner, inclusive, é citado por Freud, que faz uma apologia da ousadia deste pensador. Como desfecho de toda uma geração de pesquisas que correram "marginalmente" pelo século XIX, Ellenberger menciona o trabalho do filósofo alemão Eduard von Hartmann (1842-1906), cuja obra mais famosa está em Die Philosophie des Unbewussten (“A Filosofia do Inconsciente", de 1869), na qual o autor agrega uma extensa coletânea de fatos da vida mental, em estreita ligação com o papel desempenhado pelo inconsciente na construção e configuração destes fatos (Ellenberger, 1970).

Von Hartmann encarava o inconsciente como "um dinamismo altamente inteligente, ainda que cego, abaixo da superfície do universo físico" (Ellenberger, 1970, p. 210).

\section{Palavras Finais}

Este artigo termina com o sentimento, para não dizer a "certeza", de que não fizemos justiça à totalidade da equipe de pensadores e obras que abriram caminho para a construção do conceito de inconsciente. Deixamos, por exemplo, por pura falta de operacionalidade (dados os limites de um artigo como este), de adentrar as obras de homens como Arthur Schopenhauer (1788-1860) e Gustav Theodor Fechner (1801-1887), este último considerado por Ellenberger como um dos epígonos do Romantismo. Tanto um quanto o outro influenciaram sobremaneira algumas das idéias que vemos estampa- das hoje nas fontes secundárias que tratam de Freud e Jung, por exemplo. Por falar em "injustiças", também não pudemos adentrar em detalhes a obra do filósofo e médico francês Pierre Janet (1859-1947), um pensador que certamente mereceria um artigo inteiro só para falar em seu nome. Janet é considerado por Ellenberger como o elo de passagem do século XIX para a psiquiatria e psicologia do século XX. Dele, nos ficaram expressões conceituais como "subconsciente" e "automatismo psicológico", dentre tantas outras idéias inovadoras relacionadas ao fenômeno do inconsciente, o qual, àquela altura, já encontrava em Janet um ponto ótimo de maturidade que muito influenciaria todos os teóricos deste conceito no século XX. É realmente estranho que este autor, para quem Ellenberger dedica um capítulo inteiro em sua obra, não seja sequer citado nos planos de ensino das disciplinas de história da psicologia veiculadas no Brasil.

O escopo de pensadores mencionados aqui, extensamente tratados por Ellenberger (1970), deve ser visto não apenas como a fonte original de todo o conhecimento que hoje temos sobre o inconsciente. Devem ser encarados como o solo sobre o qual floresceram as pós-modernas teorias do inconsciente. Depois de conhecê-los, o estudo de qualquer das teorias tratadas a partir do século XX, como as de Freud, Lacan e Jung, ganha um sentido renovado. Pois aderir às idéias de um grande pensador, sem conhecer a fundo sua história, é como encontrar um chapéu perdido - você pode até vestir aquele chapéu, mas jamais saberá como era o seu dono.

\section{Referências}

Bornheim, G. (2005). Filosofia do Romantismo. Em J. Guinsburg, O Romantismo. São Paulo: Perspectiva.

Clarke, J. J. (1993). Em busca de Jung: indagações históricas e filosóficas. Rio de Janeiro: Ediouro.

Ellenberger, H. F. (1970). The discovery of the unconscious: the history and evolution of dynamic psychiatry. USA: Basic Books.

Gonçalves, M. (2006). Filosofia da natureza. Rio de Janeiro: Jorge Zahar Editor.

Leibniz, G. W. (1992). Discourse on metaphysics and the monadology. New York: Prometheus Books. (Originalmente publicado em 1920).

Nunes, B. (2005). A visão romântica. Em J. Guinsburg, $O$ Romantismo. São Paulo: Perspectiva.

Reale, G. \& Antiseri, D. (1991). História da filosofia: do Romantismo até nossos dias. São Paulo: Paulus.

Rousseau, J-J. (1995). Os devaneios do caminhante solitário. Brasília: Editora Universidade de Brasília. 
Schelling, F. W. J. (2001). Idéias para uma filosofia da natureza. Lisboa: Centro de Filosofia da Universidade de Lisboa (CFUL) \& Imprensa Nacional - Casa da Moeda (INCM).

Schultz, D. P. \& Schultz, S. E. (1996). História da psicologia moderna. São Paulo: Editora Cultrix.

César Rey Xavier - Psicólogo, Especialista em Filosofia pela Pontifícia Universidade Católica do Paraná (PUC-PR), Mestre em História da Ciência pela Pontifícia Universidade Católica de São Paulo (PUC-SP), Doutor em Filosofia da Mente pela Universidade Federal de São Carlos (UFSCar). Professor das Faculdades Dom Bosco e UniBrasil, e da Universidade do Contestado (SC). Endereço Institucional: Faculdades Dom Bosco (Campus Mercês). Rua Paulo Martins, $n^{0} 332$ - Mercês. CEP 80.710.010 - Curitiba, PR. Email: reyxavier@gmail.com

Recebido em 22.04.09 Primeira Decisão Editorial em 30.07.09 Aceito em 10.09.09 